MODELING, IDENTIFICATION AND CONTROL, 1980, vOL. 1, NO. 3, 165-186

doi: $10.4173 /$ mic.1980.3.2

\title{
Analysis of motion in single-point mooring systems
}

\author{
HANS-ROAR SØRHEIM†
}

Keywords: modelling, stability analysis, ship hydrodynamics, simulation, offshore loading.

A mathematical model of the slow motions of ships in single-point moorings is described. The model is used for analysis of stability of equilibrium positions. An analytical criterion for stability relating main system parameters is derived under simplifying assumptions. A numerical example with a $100000 \mathrm{dwt}$ tanker showed that the effect of wind and current are of equal importance with respect to system stability, and astern propulsion is generally required to avoid stable osciliations. Stability problems in waves have not been found. The effects of time varying excitations are discussed and illustrated by simulation.

\section{Introduction}

During the last ten years offshore loading in single-point mooring systems (SPMs) has become an alternative to seabed pipelines for transportation of oil from offshore production installations. From originally small units designed for a sheltered environment and shallow water depths, this concept has been used to develop systems which can withstand severe offshore weather conditions in greater water depths, so that tankers up to $150000 \mathrm{dwt}$ can be moored and loaded with a high degree of regularity.

In single-point moorings, the loading terminal, or buoy, is the only reference for the ship mooring system. Usually, the connection consists of a single elastic mooring line, the hawser, between the terminal and the ship bow, and separate hose(s) for transportation of oil. Typical hawser lengths are $40-70 \mathrm{~m}$. A variety of loading terminals exist ranging from small surface buoys to large manned structures (Maari 1975, Kapteijn 1976, van Santen and de Kerk 1976).

Weather condition is a critical factor for system performance and reliability (Haring 1976, Lenihan 1975, Koonce 1976). The relative motion between the terminal and the ship bow results in a large tension in the hawser. The cyclic nature of the tension, together with wear and tear of hawser and hose connections, degrade performance and reduce mooring system lifetime (Woehleke et al. 1978, Wheeler et al. 1973).

The understanding, prediction and possible control of these forces and motions are obviously an attractive goal.

Full scale observations (Haring 1976) model scale experiments and theoretical analysis (Pinkster and Remery 1975) show that the relative motion between ship and terminal consists of a high and a low frequency. The high frequency motion is due to ship and buoy oscillations with wave frequencies. The low frequency or slowly varying component is generally a complex motion of the moored ship which, in steady state conditions, originates from

1. asymptotically unstable equilibrium positions (stationary points) and

2. low frequency excitation from wind and waves.

Received 1 June 1979

† The Chr. Michelsen Institute, Department of Science and Technology, Bergen, Norway. This work was done during the author's stay at the University of Trondheim, The Norwegian Institute of Technology, Division of Engineering Cybernetics, with leave of absence from The Chr. Michelsen Institute, Dept. of Science and Technology, Bergen, Norway. 
Owing to small excitation force to ship mass ratios, the low frequency motion is dominated by the characteristic periods in the system. When motion amplitudes are small, these periods are distinct, and determined by spectral analysis of the linearized system. For larger motion amplitudes, when system non-linearities are excited, however, the eigenvalues become functions of motion and additional frequency components are introduced.

Except for motions of small surface buoys where the mooring hawser may add significantly to the net restoring force, the high frequency wave response of ship and terminal can usually be analysed independently. This problem is well covered by the hydrodynamic theory for motion of ships and marine structures in waves. A corresponding general theory for moored ships does not exist. Single-point mooring problems have usually been analysed experimentally using scaled physical models (model tests) (Pinkster and Remery 1975). Such experiments, however, do not clarify the underlying mechanisms essential to an understanding of complex system behaviour. During recent years, therefore, theoretical analysis has been initiated. Wichers (1976) presented a linearized analysis which shows the main influence of some system parameters upon stability. An analytical expression for stability is given by Faltinsen et al. (1979) and the effect of the equilibrium position and alternative mooring arrangements are shown. The general problem of unsteadiness and non-linearity is approached using simulation (Muga and Freeman 1977, Owen and Linfoot 1976). However, to the author's knowledge no results have been published.

In the present paper, a mathematical model for analysis of low frequency motion in single-point mooring systems is described. Local stability (i.e. stability based upon linearization) of equilibrium positions in a simplified system is derived analytically in explicit form. In the general case, the local stability problem is solved by numerical techniques. Based on a case study, the results from the simplified and linearized analysis are compared with simulations on the non-linear model. The effect of low frequency excitations and high frequency motion is indicated.

\section{Mathematical models}

The mathematical description of the single-point mooring system is divided into models of the ship, the loading terminal, the mooring system and the environment. Coupling between ship and terminal is restricted to the mooring system, ship motion is assumed independent of water depth, and there is no interaction with other structures or ships.

\subsection{The ship}

The equation of motion in surge (longitudinal motion), sway (lateral motion), and yaw (turning motion about the vertical axis) is described in a coordinate system $(x, y, z)$ fixed in the ship's centre section with positive $x$-axis forward. $x y$ and $x z$ are planes of symmetry and the ship is slender along the $x$-axis. Newton's law of motion gives (a dot above a variable stands for derivation with respect to time)

$$
\left.\begin{array}{l}
m\left(\dot{u}-v r-x_{\mathbf{g}} r^{2}\right)=X \\
m\left(\dot{v}+u r+x_{\mathbf{g}} \dot{r}\right)=Y \\
m k_{\psi \psi}{ }^{2} \dot{r}+m x_{\mathbf{g}}(\dot{v}+u r)=N
\end{array}\right\}
$$


where $(u, v, r)$ and $(X, Y, N)$ are velocity and force components in surge, sway and yaw respectively, $m$ is the mass, $k_{\psi \psi}$ the radius of gyration in yaw and $x_{\mathrm{g}}$ the position of the centre of gravity (see also Fig. 1). $(u, v)$ is the velocity relative to the surrounding water. Let $\left(\dot{x}_{r}, \dot{y}_{r}\right)$ be the ship's velocity in an earth fixed coordinate system $\left(x_{r}, y_{r}, z_{r}\right)$. Then

$$
\left.\begin{array}{l}
\dot{x}_{r}=u \cos \psi-v \sin \psi+v_{\mathrm{cu}} \cos \psi_{\mathrm{cu}} \\
\dot{y}_{r}=u \sin \psi+v \cos \psi+v_{\mathrm{cu}} \sin \psi_{\mathrm{cu}}
\end{array}\right\}
$$

where $\psi$ is ship heading or rotation of the ship fixed coordinate system relative to the earth fixed system. $\left(v_{\mathrm{cu}}, \psi_{\mathrm{cu}}\right)$ is the velocity and direction in the fixed coordinates of the ocean current.

The acceleration force is determined by the hydrodynamic reactions, manoeuvring device operation, wind, waves and mooring hawser.

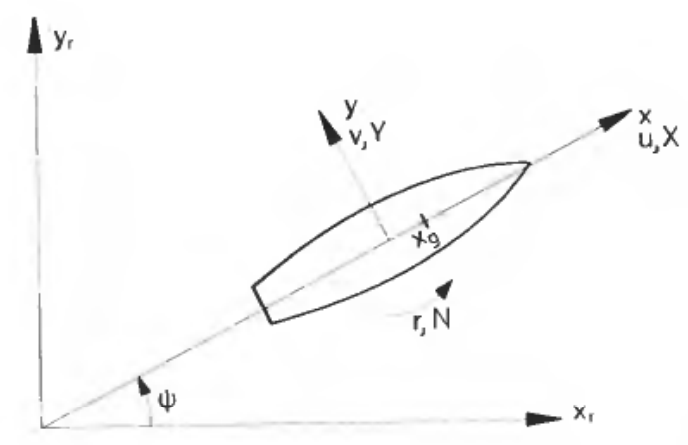

Figure 1. Ship coordinates.

\section{(a) Hydrodynamic problem}

Unlike ship motions in waves, where ideal flow theory is applicable with good results, low frequency motions of moored ships are significantly influenced by the viscous properties of the flow. Approximate theory and empirical relations, therefore, become necessary parts of these models.

The ship's oscillations with wave frequencies can be assumed independent of all low frequency motions except heading, and the high frequency wave response is calculated independently and superimposed on the low frequency motion. It is further assumed that forces associated with waves radiated by the slowly moving ships are negligible, and that mooring non-linearities do not create subharmonic motions in waves.

A common approach to the low frequency problem for ships with mean forward velocity has been to expand the hydrodynamic force in a Taylor series about this velocity, retaining a limited number of terms only (Abkowitz 1964, Crane 1966). The majority of coefficients in the expansion are assigned values by fitting the analytical expression to results from model scale experiments (Smitt and Chislett, 1974). A similar technique might also be possible when the ship is moored with zero mean forward velocity. However, unlike the 'mean forward speed' problem, which is almost linear, non-linear phenomena are essential to the 'zero speed' problem and a more

M.I.C. 
theoretical model founded in fluid mechanisms is highly desirable. Models based on this approach are described by Norrbin (1971) and Glansdorp (1975). Workable analytical expressions for different components are derived under the assumptions of ideal flow and/or simplified hull geometry. Empirically determined correction factors can be included to account for actual observed ship behaviour. The present model is based on these principles.

\section{(b) Hydrodynamic forces}

The hydrodynamic force consists of the ideal flow force and forces due to the viscosity of the flow.

Ideal flow forces (Norrbin 1971)

$$
\left.\begin{array}{l}
X_{\mathrm{id}}=-a_{x x} \dot{u}+a_{y y} v r+a_{y \psi} r^{2} \\
Y_{\mathrm{id}}=-a_{y y} \dot{v}-a_{x x} u r-a_{y \psi} \dot{r} \\
N_{\mathrm{id}}=-a_{y \psi \psi} \dot{r}-\left(a_{y y}-a_{x x}\right) u v-a_{y \psi}(\dot{v}+u r)
\end{array}\right\}
$$

where $a_{i j}$ are the so-called added mass coefficient in the $i$-direction due to motion in the $j$-direction. Note the resemblance in structure between (1) and (3). Ideal flow forces are true inertial forces uniquely determined by the geometry of the underwater hull.

Calculations of added mass are usually based on two-dimensional methods (slender ship approximation), and three-dimensional correction factors (Berg and Utnes 1978).

Lateral viscous forces are associated with hydrodynamic lift and cross-flow drag (Glandsdorp 1975). Lift dominates for small angles of attack, i.e. $|v| \ll|u|$ and $|r| L \ll|u|$. When the angle becomes larger, the flow separates with a following increase in lateral force due to the separated flow. Lift is due to circulation and is described by low-aspect-ratio wing theory and slender body theory (Newman 1977). The validity of these theories is restricted by the existence of separation which may take place for small angles of attack, $\left(<5^{\circ}\right)$. Lift, however, may exist up to much larger angles, until it finally breaks down because of stalling. This is no modelling problem, however, since lift is probably small compared to drag in the region of stall when the flow is turbulent. Cross-flow drag is described empirically.

Assuming fore-aft symmetry and three-dimensional flow, the forces due to viscosity generated lift become (Gerritsma et al. 1974)

$$
\left.\begin{array}{c}
Y_{\text {lift }}=-K_{l} \rho_{\mathrm{w}} \pi T^{2}\left(|u| v+x_{p 1}{ }^{\prime} L u r\right) \\
N_{\text {lift }}=-K_{l} \rho_{\mathrm{w}} \pi T^{2} L\left(x_{p 1}{ }^{\prime} u v+x_{p 2}{ }^{\prime 2} L|u| r\right)
\end{array}\right\}
$$

where $\rho_{\mathrm{w}}$ is density of water, $L$ the ship length, $T$ the mean draft and $K_{l}, x_{p 1}{ }^{\prime}, x_{p 2}{ }^{\prime}$ non-dimensional empirical coefficients describing the distribution of lift along the hull. Alternatively, the coefficients can be interpreted as three-dimensional correction factors or as an effective point of separation for each force-motion component (Berg and Utnes 1978).

A viscous model in surge is more complicated. For normal hull forms, however, the longitudinal forces are small compared to lateral forces, and the effect of errors is 
probably restricted to the surge motion. In this model, frictional resistance is retained, while induced drag and drag due to separation are neglected. Except for pure surge, the order of magnitude of the longitudinal force is only reasonably described in this way. The frictional drag is (van Oortmerssen and Remery 1973)

$$
X_{\text {visc }}=-\frac{1}{2} \rho_{\mathrm{w}} C_{\mathrm{dx}} S|u| u
$$

where $C_{\mathrm{d} x}$ is frictional drag coefficient and $S$ area of the under-water hull. 1975)

Similarly to lift, a two-dimensioanl cross-flow drag description gives (Glansdorp

$$
\begin{aligned}
& Y_{\text {cross-flow }}= \begin{cases}-\frac{1}{2} \rho_{\mathrm{w}} C_{\mathrm{d} y} T L \operatorname{sign}(v)\left[v^{2}+r^{2} L^{2} / 12\right] & \left|x_{p}\right| \geqslant \frac{1}{2} L \\
\rho_{\mathrm{w}} C_{\mathrm{d} y} T\left[x_{p} v^{2}+\left(x_{p}{ }^{2}-\frac{1}{4} L^{2}\right) v r+\frac{1}{3} x_{p}{ }^{3} r^{2}\right] \operatorname{sign}(r) & \left|x_{p}\right|<\frac{1}{2} L\end{cases} \\
& N_{\text {cross-flow }}=\left\{\begin{array}{cc}
-\frac{1}{12} \rho_{\mathrm{w}} C_{\mathrm{d} y} T L^{3}|v| r & \left|x_{p}\right| \geqslant \frac{1}{2} L \\
\frac{1}{2} \rho_{\mathrm{w}} C_{\mathrm{dy}} T\left[\left(x_{p}{ }^{2}-\frac{1}{4} L^{2}\right) v^{2}+\frac{4}{3} x_{p}{ }^{3} v r\right. & \left|x_{p}\right|<\frac{1}{2} L \\
\left.+\frac{1}{2}\left(x_{p}{ }^{4}-\frac{1}{16} L^{4}\right) r^{2}\right] \operatorname{sign}(r) &
\end{array}\right.
\end{aligned}
$$

$x_{p}$ is the position of zero effective cross-flow, $x_{p}=-v / r$, and $C_{\mathrm{d} y}$ the mean lateral drag coefficient determined from a three-dimensional model test in lateral flow. This model is reasonably good in pure translation, but questionable for rotational motion where actual distribution of lateral drag along the hull is important (English 1970).

The fore-aft symmetry used in the viscous force model may be a crude approximation. Differences in bow and stern sections, trim, appendages, propulsion jets, etc. contribute to a non-symmetric model. Empirical data, or preferably experiments with the particular hull, are usually required to deal with these effects.

\section{(c) Manoeuvring device forces}

In addition to conventional manoeuvring devices, main propulsion and rudder, tankers used in offshore loading operations may be equipped with bow and stern lateral thrusters to increase manoeuvrability near the loading terminal. In this analysis active control is not considered. Main propeller demand is zero or equal to a fixed astern thrust value. The rudder is fixed in the neutral (zero) position.

Propulsion and rudder forces are coupled, and, in particular, rudder efficiency depends heavily upon propeller action when ship forward velocity is small. In zero or astern thrust condition, the rudder force is estimated using the method described by van Berlekom (1975) and Brummer et al. (1972). For the purpose of analysis, these forces can be considered included in the viscous model of the ship's hull forces.

\section{(d) Wind forces}

The wind force consists of viscous shear forces, pressure forces due to separated flow, and lift forces due to circulation. The wind force model is based on the empirical drag coefficients $C^{\text {wind }}(\alpha)$ in surge, sway and yaw (van Oortmerssen and Remery 1973)

$$
\left.\begin{array}{l}
X_{\text {wind }}=\frac{1}{2} \rho_{\mathrm{a}} C_{x}{ }^{\text {wind }}(\alpha) A_{\mathrm{T}} V^{2} \\
Y_{\text {wind }}=\frac{1}{2} \rho_{\mathrm{a}} C_{y}{ }^{\text {wind }}(\alpha) A_{\mathrm{L}} V^{2} \\
N_{\text {wind }}=\frac{1}{2} \rho_{\mathrm{a}} C_{\psi}{ }^{\text {wind }}(\alpha) A_{\mathrm{L}} L V^{2}
\end{array}\right\}
$$


where $\rho_{\mathrm{a}}$ is density of air, $A_{\mathbf{T}}$ and $A_{\mathrm{L}}$ the transverse and lateral exposed wind area, $\alpha$ the angle of attack and, $V$ the relative velocity of wind. Let $\left(v_{\mathrm{wi}}, \psi_{\mathrm{wi}}\right)$ be the wind velocity and direction in fixed coordinates. Then $\alpha=\psi_{\mathrm{wi}}-\psi$ and $V^{2}=v_{\mathrm{wl}}{ }^{2}+$ order $(u, v)$. The order $(u, v)$ terms represent aerodynamic damping. In mooring problems these terms are usually neglected compared with the hydrodynamic damping forces.

\section{(e) Wave forces}

The mathematical description of slowly varying wave forces has been the subject of extensive research in recent years. It has been found that the excitation forces and moments in irregular waves can be described in terms of the forces and moments in regular waves, and different approaches to this problem have been suggested (Faltinsen and Løken 1978). In this model, the slowly varying wave force is calculated from the second-order transfer function in regular waves as described in Fig. 2 (Hsu and Blenkarn 1970).

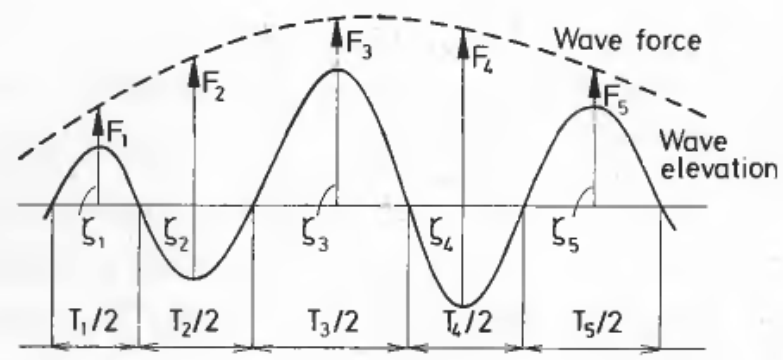

Figure 2. Slowly varying wave force.

Subsequent zero-crossings of the wave define the half-period, $T_{i} / 2$, and the wave height, $\zeta_{i}$, of a regular wave. The second-order wave force, $F_{i}{ }^{\text {wa }}$, associated with this regular wave is

$$
F_{\mathrm{i}}{ }^{\mathrm{wa}}=\frac{1}{2} \rho_{\mathrm{w}} g R^{2}\left(T_{l}\right) \zeta_{l}{ }^{2} L
$$

where $g$ is the acceleration due to gravity and $R$ the second-order wave force transfer function in regular waves. A continuous function is generated by interpolation.

$R$ usually depends on the relative wave heading in a complex way. In this model, a simplified symmetrical relation is used

$$
\left.\begin{array}{l}
X_{\text {wave }}=F_{x}{ }^{\text {wa }}\left|\cos \left(\psi_{\mathrm{wa}}-\psi\right)\right| \cos \left(\psi_{\mathrm{wa}}-\psi\right) \\
\boldsymbol{Y}_{\mathrm{wave}}=F_{y}{ }^{\text {wa }}\left|\sin \left(\psi_{\mathrm{wa}}-\psi\right)\right| \sin \left(\psi_{\mathrm{wa}}-\psi\right) \\
N_{\text {wave }}=F_{\psi}{ }^{\mathrm{wa}} \sin 2\left(\psi_{\mathrm{wa}}-\psi\right)
\end{array}\right\}
$$

where $\psi_{\mathrm{wa}}$ is wave direction and $\boldsymbol{F}_{\boldsymbol{x}}{ }^{\mathrm{wa}}, \boldsymbol{F}_{\boldsymbol{y}}{ }^{\mathrm{wa}}$ and $\boldsymbol{F}_{\psi}{ }^{\mathrm{wa}}$ the surge, sway and yaw wave force in head, beam and bow waves respectively. It is emphasized that the errors involved using (9) may be quite large. Alternative and possibly more accurate approximate expressions are given by Faltinsen et al. (1979). 


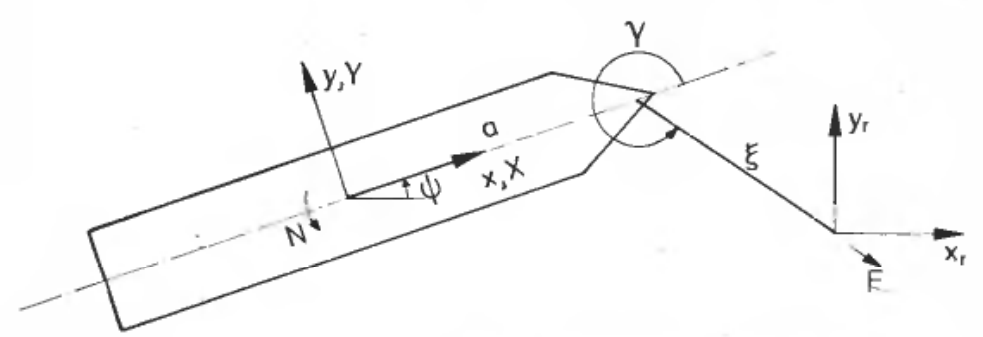

Figure 3. Moored ship coordinates.

\section{(f) Mooring forces}

The mooring hawser force, $F$, acts at the bow in position: $x=a$, (Fig. 3 ),

$$
\left.\begin{array}{l}
X_{\text {hawser }}=F \cos \gamma \\
Y_{\text {hawser }}=F \sin \gamma \\
N_{\text {hawser }}=a F \sin \gamma
\end{array}\right\}
$$

$\gamma$ is the hawser direction relative to the ship heading.

\subsection{The loading terminal}

The variety of loading terminals is such that a general type model of fluid reaction forces on the terminal is not practical. The articulated loading platform (ALP) is used in this study. The ALP is a bottom pivoting, rigid and slender tower with a buoyancy module which gives vertical stability.

For large tankers, the equivalent surge buoy inertia (ALP) is typically $5 \%$ or less of the ship inertia. In the low frequency range, the effect of the buoy is therefore to increase mooring system elasticity compared with the elasticity of the hawser alone, and it is easily included in the mooring system model. The high frequency buoy motion, however, is the dominating source of high frequency ship-buoy separation and hawser tension.

\subsection{The mooring system}

The mooring system, consisting of a single mooring hawser between the ship bow and the buoy, is modelled by its static force-elongation characteristic, $f_{\mathrm{h}}$, and length in unloaded condition, $l_{00}$. Hawser tension force is

$$
F= \begin{cases}0 & l \leqslant l_{00} \\ f_{\mathrm{h}}\left(\frac{l-l_{00}}{l_{00}}\right) & l>l_{00}\end{cases}
$$

$f_{\mathrm{h}}$ is usually very non-linear (Woehleke et al. 1978) and is modelled by an interpolating curve. When the buoy model is static and the buoy restoring force included 
in the mooring model, the hawser tension becomes

$$
F= \begin{cases}0 & \xi \leqslant l_{00} \\ f_{\mathrm{m}}\left(\frac{\xi-l_{00}}{l_{00}}\right) & \xi>l_{00}\end{cases}
$$

where the mooring line length, $\xi$, is the distance between ship bow and vertical buoy position. $f_{\mathrm{m}}(\cdot)$ is determined numerically from the following implicit relation (small buoy tilt)

$$
F=f_{\mathrm{h}}\left(\frac{\xi-l_{00}}{l_{00}}-\frac{F / k_{\mathrm{b}}}{l_{00}}\right)
$$

where $k_{\mathrm{b}}$ is the restoring coefficient of the buoy at the hawser connection point.

\subsection{The environment}

Wind is modelled as a two-dimensional stationary, zero-mean gaussian gust process superimposed on a steady state mean wind. The spectral properties of both gust components are equal and approximations to the turbulence spectrum are proposed by Harris (Sigbjørnson 1975)

$$
\Phi_{v_{\mathrm{g}} v_{\mathrm{g}}}(v)=\frac{2 \kappa \Lambda \bar{v}_{\mathrm{wi}}}{\left(2+v^{2}\right)^{5 / 6}}
$$

with

$$
v=\frac{\Lambda \omega}{2 \pi \bar{v}_{\mathrm{wi}}}
$$

$\Lambda$ and $\kappa$ are spectrum parameters, $\bar{v}_{\mathrm{wi}}$ the mean wind velocity, $v_{\mathrm{g}}$ the gust velocity and $v$ the non-dimensional gust frequency. This is almost the spectrum of a first-order process. A time domain representation which approximates (14) to first order in $v^{2}$ is

$$
\left.\begin{array}{l}
\dot{q}=c_{1} q+c_{2} z \\
v_{\mathbf{g}}=c_{3}(q+z)
\end{array}\right\}
$$

where

$$
c_{1}=-\frac{2 \sqrt{ } 2 \pi \bar{v}_{\mathrm{wi}}}{\Lambda}, \quad c_{2}=\frac{2 \pi \bar{v}_{\mathrm{wi}}\left[\sqrt{ }\left(12+5 v_{0}{ }^{2}\right)-\sqrt{ } 2\right]}{\Lambda}, \quad c_{3}=\frac{\sqrt{ }\left(\kappa \Lambda \bar{v}_{\mathrm{wi}}\right)}{\sqrt{\left[3\left(2+v_{0}^{2}\right)^{5 / 6}\right]}}
$$

and $z$ is a zero-mean, gaussian, white noise process with unit variance and $v_{0}$ the nondimensional frequency of linearization.

Irregular waves are described as the sum of regular small amplitude waves with random phase. The amplitude and frequency of each wave component is calculated from a typical ocean wave spectrum (Minkenberg and Gie 1974). If $S_{\zeta}(\omega)$ is the Pierson-Moskowitz wave spectrum with significant wave height $H_{5}$, a simulated 
wave amplitude, $\zeta(t)$, is described by

$$
\zeta(t)=\sum_{i=1}^{n} \zeta_{i} \cos \left(\omega_{i} t+\varepsilon_{l}\right)
$$

with

$$
\begin{aligned}
\zeta_{i} & =\left[2 S_{\zeta}\left(\omega_{i}\right)\left(\omega_{i}-\omega_{i-1}\right)\right]^{\frac{1}{2}} \\
\omega_{i} & =\left\{\omega \mid \frac{16}{H^{2}} \int_{0}^{\omega} S_{\zeta}(\omega) d \omega=\alpha_{i}, \omega_{i+1}>\omega_{i}\right\}
\end{aligned}
$$

where $\alpha_{i}$ and $\varepsilon_{i}$ are drawn from uniform distributions of random numbers on the interval $[0,1]$ and $[0,2 \pi]$ respectively.

Current has a constant value.

\subsection{Model evaluation and simulation}

The general structure of the simulation model is summarized in the Appendix. The model of slowly varying motion dynamics is of sixth order and non-linear. Typical solution curves consist of forced or slightly damped oscillations. Inherent stable oscillations, limit cycles, may also be experienced as a result of the model nonlinearities.

Since the model structure is relatively well known, correspondence between model prediction and physical system behaviour is, within reasonable accuracy requirements, a function of the model parameter values available for the actual system. In this study, the model is used to analyse the motion of a $100000 \mathrm{dwt}$ tanker moored to an ALP in $150 \mathrm{~m}$ water depth. A detailed parameter assignment process for the ship has not been carried out, and model parameters are estimates based on published data for similar hulls. Main system data are listed in Table 1 and a comparison of non-dimensional ship coefficients with those of two other tankers are shown in Table 2. Buoy and hawser data are from model test experiments.

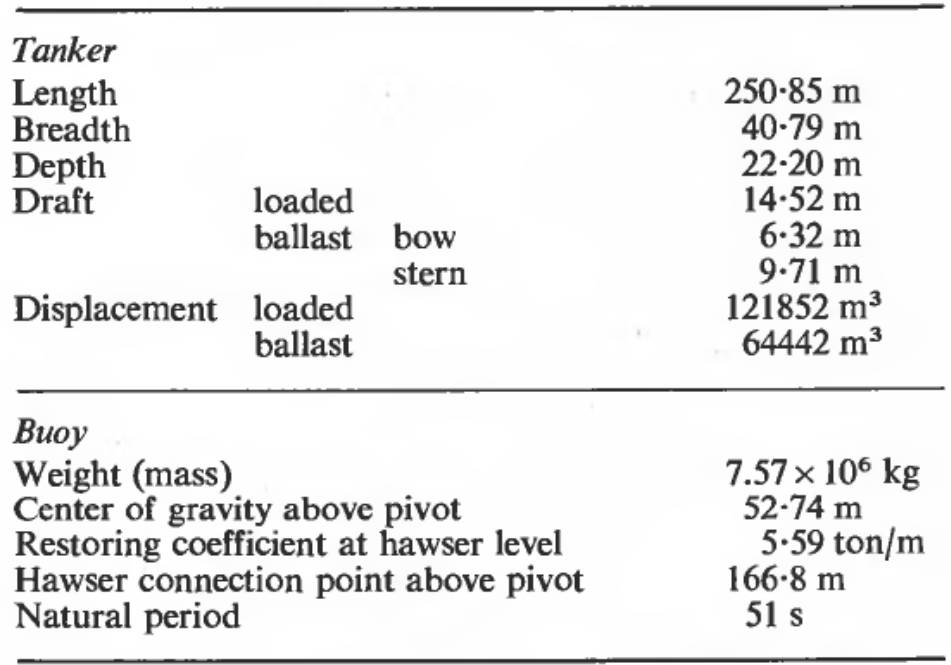

Table 1. Buoy and tanker main data. 


\begin{tabular}{|c|c|c|c|c|c|}
\hline \multirow{2}{*}{ Coefficient } & \multicolumn{2}{|c|}{$\begin{array}{l}\text { SPM tanker } \\
126000 \text { dwt }\end{array}$} & \multicolumn{2}{|c|}{$\begin{array}{c}\text { Ship A } \\
282000 \mathrm{dwt}\end{array}$} & \multirow{2}{*}{$\begin{array}{c}\text { Ship B } \\
100000 \text { dwt } \\
\text { loaded }\end{array}$} \\
\hline & loaded & ballast & loaded & ballast & \\
\hline $1-X_{\dot{u}}^{\prime \prime}$ & 1.05 & $1 \cdot 05$ & $1 \cdot 060$ & $1 \cdot 060$ & 1.05 \\
\hline$X^{n}$ นи & -0.0462 & -0.0686 & -0.0300 & -0.0400 & -0.0456 \\
\hline $1+X_{v r}^{\prime \prime}$ & 1.90 & $1 \cdot 70$ & $1 \cdot 535$ & $1 \cdot 337$ & $2 \cdot 02$ \\
\hline $1-t$ & $0 \cdot 8$ & $0 \cdot 8$ & $0 \cdot 82$ & $0 \cdot 81$ & $0 \cdot 78$ \\
\hline $1-Y_{v}^{\prime \prime}$ & $1 \cdot 90$ & $1 \cdot 70$ & 1.973 & $1 \cdot 671$ & $2 \cdot 02$ \\
\hline$Y_{\dot{r}}-x_{\mathrm{g}}^{\prime \prime}$ & -0.027 & -0.009 & $-0 \cdot 081$ & $-0 \cdot 050$ & \\
\hline $1-Y^{\prime \prime}{ }_{u r}^{\circ}$ & 0.695 & 0.720 & 0.684 & 0.686 & 0.752 \\
\hline$Y^{\prime \prime}{ }_{u v}$ & $-1 \cdot 119$ & -0.886 & -0.941 & -0.864 & $-1 \cdot 205$ \\
\hline & $-2 \cdot 25$ & $-2 \cdot 35$ & $-2 \cdot 70$ & $-2 \cdot 57$ & $-2 \cdot 385$ \\
\hline & $0 \cdot 200$ & 0.305 & $0 \cdot 167$ & $0 \cdot 200$ & 0.208 \\
\hline$k_{\psi \psi \psi}^{\prime \prime}{ }^{2}-N_{i}^{\prime \prime}$ & $0 \cdot 109$ & 0.094 & $0 \cdot 109$ & 0.099 & $0 \cdot 1232$ \\
\hline$N_{i v}^{n}-x_{\mathbf{g}}^{\prime \prime}$ & -0.027 & -0.009 & -0.061 & -0.042 & \\
\hline$N^{\prime \prime}{ }_{u r}-x^{\prime \prime}{ }_{\mathrm{g}}$ & -0.214 & $-0 \cdot 186$ & $-0 \cdot 196$ & $-0 \cdot 184$ & $-0 \cdot 231$ \\
\hline$N^{\prime \prime}{ }_{w v}$ & -0.495 & $-0 \cdot 320$ & -0.495 & -0.310 & -0.451 \\
\hline$N^{\prime \prime}{ }_{|v| r}$ & -0.375 & -0.392 & -0.354 & $-0 \cdot 265$ & $-0 \cdot 300$ \\
\hline$N^{\prime \prime}{ }_{c c \delta}^{\prime \prime}$ & $-0 \cdot 100$ & $-0 \cdot 153$ & -0.077 & 0.093 & -0.098 \\
\hline
\end{tabular}

Table 2. Non-dimensional hydrodynamic coefficients compared with published data for $282000 \mathrm{dwt}$ tanker (van Berlekom et al. 1974) and $100000 \mathrm{dwt}$ tanker (van Berlekom and Goddard 1972). Coefficients are non-dimensionalized according to the 'bis' system (Norrbin 1971).

The model is simulated by integrating the non-linear, differential equations numerically. Since the ratio between the largest and the smallest real part of the system eigenvalues is moderate (typically less than 100), the problem is not considered stiff, and only explicit integration techniques have been tried. Among a fourth-order predictor-corrector method and different order Runge-Kutta methods, the secondorder method of Runge-Kutta proved to be the most efficient, yet differences were small. A fixed step-length, usually $1-5 \mathrm{~s}$, have been employed.

\section{Analysis of motion in single-point mooring syste as}

The order and non-linear character of the model described restrict explicit form analytical results to cases involving simplifications and restrictions on the models and solutions. A more general analysis is based on studies of solution curves found by numerical integration of the differential equations with given critical conditions.

Analysis of stability of equilibrium positions is a main topic of this section. The analytical part is restricted to local stability since the analysis assumes linearization. By further restricting the excitations to be collinear and neglect system damping, explicit form analytical expressions for the stability requirements are derived.

\subsection{Equilibrium positions}

When the ship is supported by a single mooring force, the determination of equilibrium positions can be carried out sequentially starting with the equilibrium ship heading. 
Let index 0 denote values at equilibrium. Ship heading, $\psi_{0}$, is determined by the equation of moment equilibrium at the mooring hawser connection point

$$
N\left(\psi_{0}\right)-a Y\left(\psi_{0}\right)=0
$$

This is a non-linear equation which usually has to be solved numerically. Only solutions $\psi_{0} \in[-\pi / 2, \pi / 2]$ are of interest (Fig. 3). When $\psi_{0}$ is calculated, $\boldsymbol{F}_{0}$ and $\gamma_{0}$ are determined from $X\left(\psi_{0}\right)$ and $Y\left(\psi_{0}\right)$, and additional forces and positions by using the mooring force characteristics and trigonometric relations.

$\psi_{0}$ is determined by environmental forces and lateral manoeuvring forces. Note that astern propulsion does not affect $\psi_{0}$, but can be used to reduce $\gamma_{0}$. Símilarly $\psi_{0}$ can be controlled by a lateral thruster, preferably located as near the stern as possible. A bow thruster, on the other hand, is practically useless for controlling mean ship heading.

\subsection{Linearized analysis of stability}

Linearization of the general low frequency model yields a system of six first-order differential equations, and a sixth order characteristic polynomial for determination of eigenvalues. The stability can be analysed numerically by either solving for the eigenvalues, or using Routh's criterion for stability. Analytical analysis of stability is only feasible under conditions where the characteristic polynomial has a particular simple form. Such a form is obtained if the problem is symmetric, for example if wind, wave and current all come from ahead in a possible equilibrium position. Assume that this condition exists and, for simplicity, that $x_{\mathrm{g}}=a_{y \psi}=0$ in (1) and (3).

\section{(a) Simplified stability theory}

In order to simplify the mooring force description and obtain an explicit expression for the current force, a new set of linear position and velocity coordinates, $(\xi, \gamma)$ and $\left(v_{x}, v_{y}\right)$, are introduced. $(\xi, \gamma)$ is the mooring line length and direction relative to the ship heading, and $\left(v_{x}, v_{y}\right)$ is the longitudinal and lateral velocity of the ship over ground. Assume that $\gamma+\psi \in[-\pi / 2, \pi / 2]$, then

$$
\left.\begin{array}{l}
x_{r}=-\xi \cos (\gamma+\psi)-a \cos \psi \\
y_{r}=-\xi \sin (\gamma+\psi)-a \sin \psi
\end{array}\right\}
$$

and

$$
\left.\begin{array}{c}
v_{x}=u+v_{\mathrm{cu}} \cos \left(\psi_{\mathrm{cu}}-\psi\right) \\
v_{y}=v+v_{\mathrm{cu}} \sin \left(\psi_{\mathrm{cu}}-\psi\right)
\end{array}\right\}
$$

completely describe this transformation. The kinematics of motion (2) in new coordinates becomes

$$
\left.\begin{array}{c}
\dot{\xi}=-v_{x} \cos \gamma-\left(v_{y}+a r\right) \sin \gamma \\
\xi \dot{\gamma}=v_{x} \sin \gamma-\left(v_{y}+a r\right) \cos \gamma-\xi r
\end{array}\right\}
$$


and the symmetric linearized problem becomes

$$
\left.\begin{array}{rl}
\dot{\xi} & =-v_{x} \\
\xi_{0} \dot{\gamma} & =-v_{y}-\left(a+\xi_{0}\right) r \\
\psi & =r \\
M_{x} \dot{v}_{x} & =X_{v} v_{x}+F_{\xi} \xi \\
M_{y} \dot{v}_{y} & =Y_{v} v_{y}+Y_{r} r+F_{0} \gamma+Y_{\psi}^{\text {en }} \psi \\
I_{z} \dot{r} & =N_{v} v_{y}+N_{r} r+a F_{0} \gamma+N_{\psi}^{\text {en }} \psi
\end{array}\right\}
$$

where $M_{x}, M_{y}$ and $I_{z}$ are virtual masses, $M_{x}=m+a_{x x}$, etc. $X_{v}=\partial X\left|\partial v_{x}\right|_{v_{x}=0}$ is the force derivative in surge due to surge velocity $v_{x}$, and similar for the other derivatives. $Y_{\psi}{ }^{\text {en }}$ and $N_{\psi}{ }^{\text {en }}$ are environmental force derivatives including wind, waves and current.

From (21) it is observed that the surge mode is decoupled from the sway-yaw modes. Clearly the ship is stable in surge $\left(X_{v}<0\right)$. The sway-yaw part of the characteristic polynomial becomes

$$
\lambda^{4}+A \lambda^{3}+B \lambda^{2}+C \lambda+E=0
$$

with coefficients

$$
\begin{aligned}
& A=-\frac{Y_{v}}{M_{y}}-\frac{N_{r}}{I_{z}} \\
& B=\frac{Y_{v} N_{r}-Y_{r} N_{v}}{M_{y} I_{z}}+F_{0}\left[\frac{1}{\xi_{0} M_{y}}+\frac{a^{2}}{\xi_{0} I_{z}}+\frac{a}{I_{z}}\right]-\frac{N_{\psi}^{\text {en }}}{I_{z}} \\
& C=\frac{F_{0}}{M_{y} I_{z}}\left[\left(1+\frac{a}{\xi_{0}}\right)\left(N_{v}-a Y_{v}\right)-\frac{1}{\xi_{0}}\left(N_{r}-a Y_{r}\right)\right]-\frac{Y_{\psi}^{\text {en }} N_{v}-N_{\psi}^{\text {en }} Y_{v}}{M_{y} I_{z}} \\
& E=\frac{F_{0}}{\xi_{0} M_{y} I_{z}}\left(a Y_{\psi}^{\text {en }}-N_{\psi}^{\text {en }}\right)
\end{aligned}
$$

From Routh local stability is achieved for $A>0, B>0, C>0, E>0$ and $A B C-C^{2}-$ $A^{2} E>0$, and actual values must be inserted to obtain workable expressions.

A particularly interesting case arises if damping is very small, as an approximation, is set to zero. Then $A=C=0$ and (22) becomes

$$
\lambda^{4}+B \lambda^{2}+E=0
$$

with solutions

$$
\lambda_{1} \cdots_{4}= \pm\left(-\frac{B}{2} \pm \frac{1}{2}\left(B^{2}-4 E\right)^{\frac{1}{2}}\right)^{\frac{1}{2}}
$$

Assume $B>0$ (note that $E>0$ is automatically implied from a stable equilibrium heading, i.e. $\partial / \partial \psi(N(\psi)-a Y(\psi))<0$ for $\left.\psi=\psi_{0}\right)$. The eigenvalues are then complex conjugated in pairs and purely imaginary when $B^{2}-4 E>0$, and complex conjugated with one stable and one unstable pair of solutions when $B^{2}-4 E<0$, (Fig. 4). 

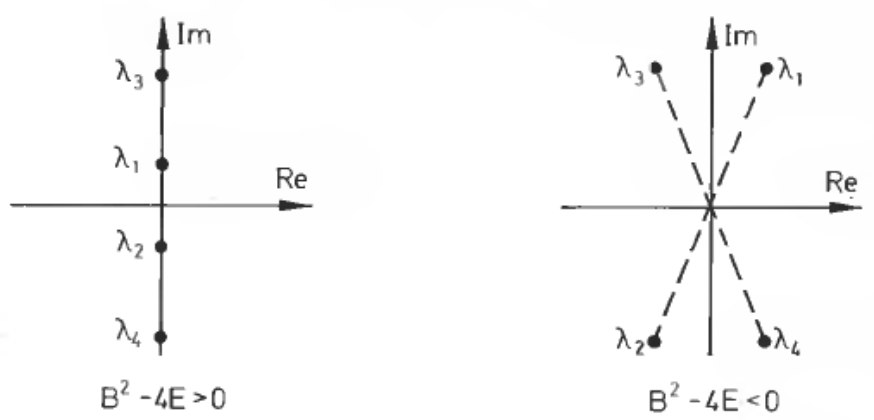

Figure 4. Eigenvalues of symmetric problem without damping.

The critical condition is obviously $B^{2}-4 E=0$, and local stability is achieved for, $(B>0)$.

$$
B^{2}-4 E>0
$$

With (25) satisfied, any positive damping stabilizes the system locally. For $B^{2}-4 E<0$ the system is obviously locally unstable without damping. If a positive damping exists, the system may still become locally stable provided the damping is large enough to shift the unstable eigenvalues into the left-half plane. Condition (25) is then unduly restrictive, and stability requirements must be based on the analysis of (22).

By working out condition (25) it becomes

$$
f\left(\xi_{0}, F_{0}\right)=\alpha \xi_{0}^{2}+\beta \xi_{0}+\sigma \geqslant 0
$$

with

$$
\begin{aligned}
& \alpha=\left(a F_{0}-N_{\psi}^{\text {en }}\right)^{2} \\
& \beta=2 F_{0}\left[\left(I_{z} / M_{y}+a^{2}\right)\left(a F_{0}-N_{\psi}^{\text {en }}\right)-2 I_{z} / M_{y}\left(a Y_{\psi}^{\text {en }}-N_{\psi}^{\text {en }}\right)\right] \\
& \sigma=F_{0}^{2}\left(I_{z} / M_{y}+a^{2}\right)^{2}
\end{aligned}
$$

The characteristics of $f\left(\xi_{0}, F_{0}\right)=0$ and $B=0$ are sketched in Fig. 5 for $N_{\psi}^{\text {en }}>0$.

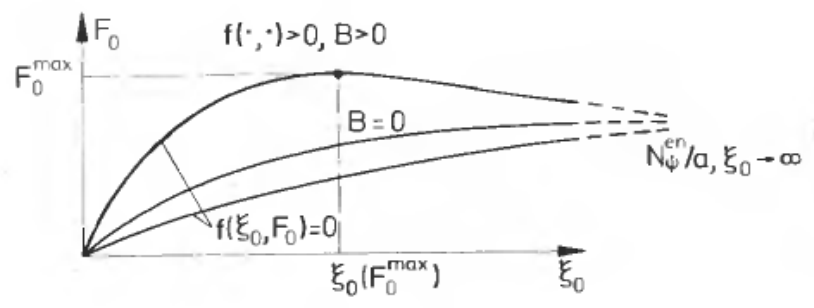

Figure 5. Sketch of stability conditions $B=0$ and $B^{2}-4 E=0$.

For hawser tension $F_{0} \geqslant F_{0}{ }^{\text {max }}$ the system is locally stable for any mooring line length, $\xi_{0}$. When $F_{0}<F^{\max }$, stability is only possible if $-\xi_{0}<\xi_{1}$ or $\xi_{0}>\xi_{2}$, where $\xi_{1}$ and $\xi_{2}$ are the roots of the equality (26). Only the smaller root is of practical interest and is denoted the critical value, $\xi_{0}{ }^{\text {crit }} . \xi_{0}$ crlt defines a stability line for the system, or a 
relation between hawser tension and mooring line length which is critical with respect to stability. The solutions are found to be

$$
F_{0}{ }^{\max }=\frac{I_{z} / M_{y} Y_{\psi}^{\mathrm{en}}+a N_{\psi}^{\mathrm{en}}}{I_{z} / M_{y}+a^{2}}
$$

and

$\xi_{0}^{\mathrm{crlt}}=F_{0}\left\{\frac{I_{z} / M_{y}+a^{2}}{\left[I_{z} / M_{y}\left(a Y_{\psi}^{\text {en }}-N_{\psi}^{\text {en }}\right)\right]^{\frac{1}{2}}+\left[a\left[I_{z} / M_{y}\left(Y_{\psi}^{\text {en }}-F_{0}\right)-a\left(a F_{0}-N_{\psi}^{\text {en }}\right)\right]\right]^{\frac{1}{2}}}\right\}^{2}$

the inverse function is

$F_{0}{ }^{\text {crit }}=\xi_{0}\left\{\frac{\left[I_{z} / M_{y}\left(a Y_{\psi}^{\text {en }}-N_{\psi}^{\text {en }}\right)\right]^{\frac{1}{2}}+\left[a\left[I_{z} / M_{y} Y_{\psi}^{\text {en }}+\left(\xi_{0}+a\right) N_{\psi}^{\text {en }}\right]\right]^{\frac{1}{2}}}{I_{z} / M_{y}+a\left(\xi_{0}+a\right)}\right\}^{2}$

In the collinear case, $\gamma_{0}=0$ and $\psi_{0}=\psi^{\mathrm{en}}+\pi$, the hawser tension is the algebraic sum of longitudinal environmental force, $X^{\mathrm{en}}$, and astern thrust, $T_{\mathrm{a}}$, i.e. $F_{0}=X^{\mathrm{en}}+T_{\mathrm{a}}$, and (27)-(29) is a relation between astern thrust and mooring line length.

If $N^{\text {en }}<0$, then $f\left(\xi_{0}, F_{0}\right)>0$ for any $F_{0}$ provided $\xi_{0}>\xi_{0}{ }^{\max }$. However, both $F_{0}{ }^{\max }$ and $\xi_{0}{ }^{\max }$ are small and without practical interest.

The main result of this analysis is

$$
\text { If } F_{0}>F_{0}{ }^{\max } \text { the ship is locally stable for any mooring line length. }
$$

When $F_{0}<F_{0}{ }^{\max }$ the ship is locally stable if $\xi_{0}<\xi_{0}{ }^{\text {crit }}$.

The results (27) and (28) are equal to those presented by Faltinsen et al. (1979). From the formulae it follows that stability increases when $F_{0}{ }^{\max }$ decreases, i.e. for a large and $N_{\psi}{ }^{\text {en }}$ small, and similarly when $\xi_{0}{ }^{\text {crit }}$ increases, i.e. $F_{0}$ large, $a$ and $I_{z} / M_{y}$ large and $Y_{\psi}^{\text {en }}$ small.

\section{(b) Numerical results}

Wind and wave parameter values are taken from (OCIMF 1977) and Faltinsen and Løken (1978). Mean wave drift forces were not found to create any stability problem in this analysis. Calculated values of $F_{0}{ }^{\max }$ were less than hawser tensions due to waves. Values for $F_{0}{ }^{\text {max }}$ and $\xi_{0}\left(F_{0}{ }^{\max }\right)$, (see Fig. 5), for wind and current are given in Table 3.

Units used are ton, meter, degree and second.

\begin{tabular}{lcccc}
\hline & \multicolumn{2}{c}{ Wind } & \multicolumn{2}{c}{ Current } \\
\cline { 2 - 5 } & $F_{0}{ }^{\max } / v^{2}{ }_{\mathrm{w1}}$ & $\xi_{0}\left(F_{\mathrm{o}}{ }^{\max }\right)$ & $F_{0}{ }^{\max } / v^{2}{ }_{\mathrm{cu}}$ & $\xi_{0}\left(F_{0}{ }^{\max }\right)$ \\
\hline Ballast & $0 \cdot 109$ & 940 & $18 \cdot 0$ & 2280 \\
Loaded & 0.0027 & 21 & $50 \cdot 5$ & 5680 \\
\hline
\end{tabular}

Table 3. Necessary hawser tension and worst condition mooring line length for unconditional local stability of tanker in wind and current. 
A relatively large level of hawser tension may be necessary if unconditional local stability is required. Furthermore, in terms of astern thrust, current excitation in loaded conditions seems to be the worst condition $\left(F_{0} \simeq T_{\mathrm{a}}\right.$ in current). The small values in wind, loaded condition, is due to $N_{\psi}{ }^{\mathrm{w1}}<0$, which is an extremely stable condition.

For practical values of mooring line lengths, the stability lines, in terms of astern thrust to velocity of excitation squared, are drawn for wind (Fig. 6), and current (Fig. 7).

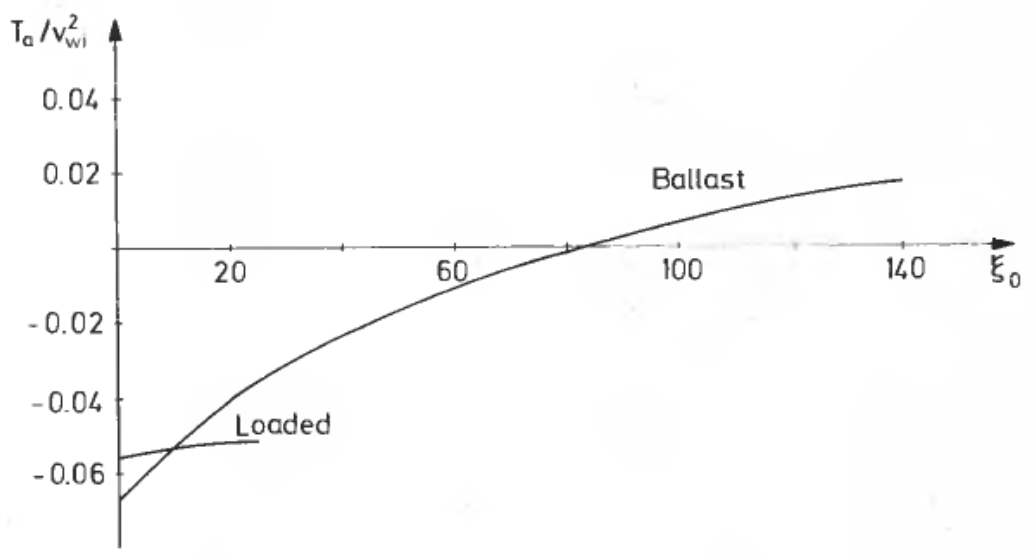

Figure 6. Stability lines in wind.

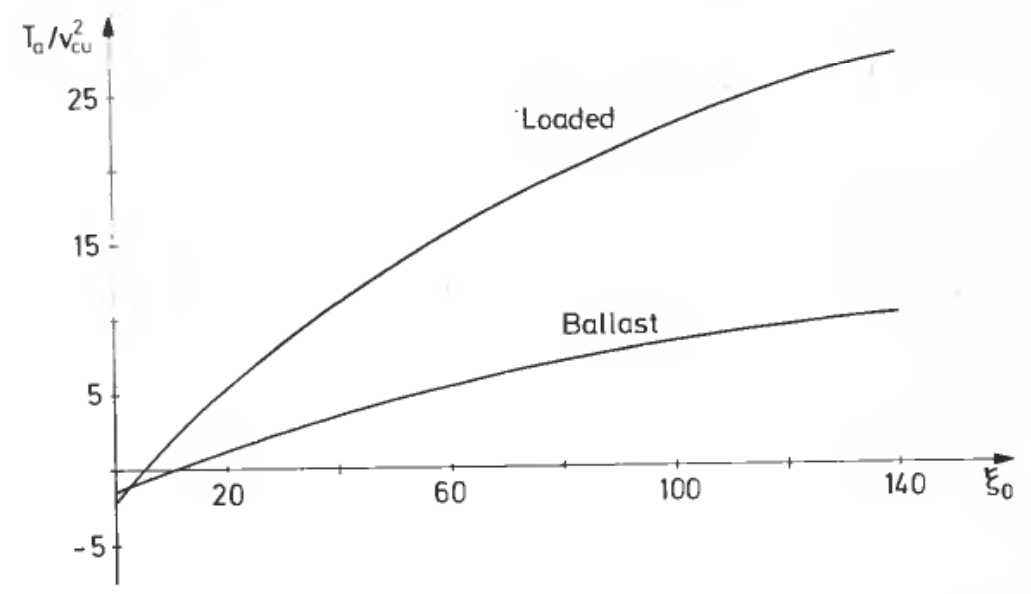

Figure 7. Stability lines in current.

The effect of damping has been studied by comparison with results from the stability polynomial, (22), using Routh's criterion. With wind excitation, the difference was negligible (aerodynamic damping small) while hawser tension or astern thrust requirement was significantly reduced in current as a result of hydrodynamic damping (Fig. 8). 


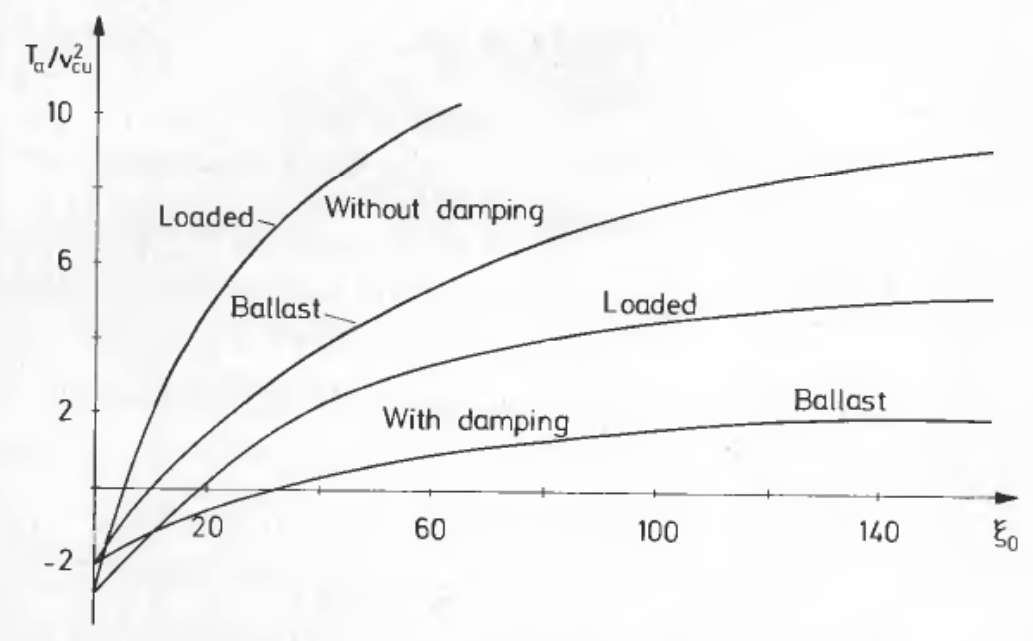

Figure 8. Effect of damping on stability in current.

It is emphasized that $\xi_{0}$ includes both hawser and buoy elasticity and may be considerably larger than zero tension separation distance.

An analysis of stability of equilibrium positions for the general linearized sixthorder system have been carried out by solving the eigenvalue problem numerically. The results of this study are similar to those described by Wichers (1976). Stability increases with increasing angle between excitation components, wind, waves and current, and with increasing angle of attack when excitations are collinear. Hawser length and tension have the same influence upon stability as for the simplified system already described.

\subsection{Evaluation of linearized analysis - non-linear effects}

Stability in linear (and linearized) systems implies local asymptotic stability. If the linearized system is unstable, the ship goes into stable oscillations in a limit cycle. Global or unconditional asymptotic stability in a non-linear system is an equal or stronger requirement than local stability (by assumption this system definition does not allow for hawser breakage). A suitable Lyapunov function for this problem has not been established, and the analysis is therefore based on numerical experiments with large motion amplitudes using simulation. The results showed that the linearized stability line in current (Fig. 7) is indeed a global asymptotic stability line. The same, however, is not true in wind, and the global asymptotic stability line, as found from simulations, is shown in Fig. 9.

This increase in stability requirement in wind is probably due to the non-linear hydrodynamic force reactions not present in the linearized analysis. It is therefore interesting to observe that while hydrodynamic damping is stabilizing in current, it has an opposite effect in wind, compared with the simplified linearized analysis.

When the ship is in stable oscillations in a limit cycle, the motion is completely determined by the non-linear properties of excitation, damping and mooring system forces. Frequently, the motion shows a combined fish-tailing and galloping form (Fig. 10). 


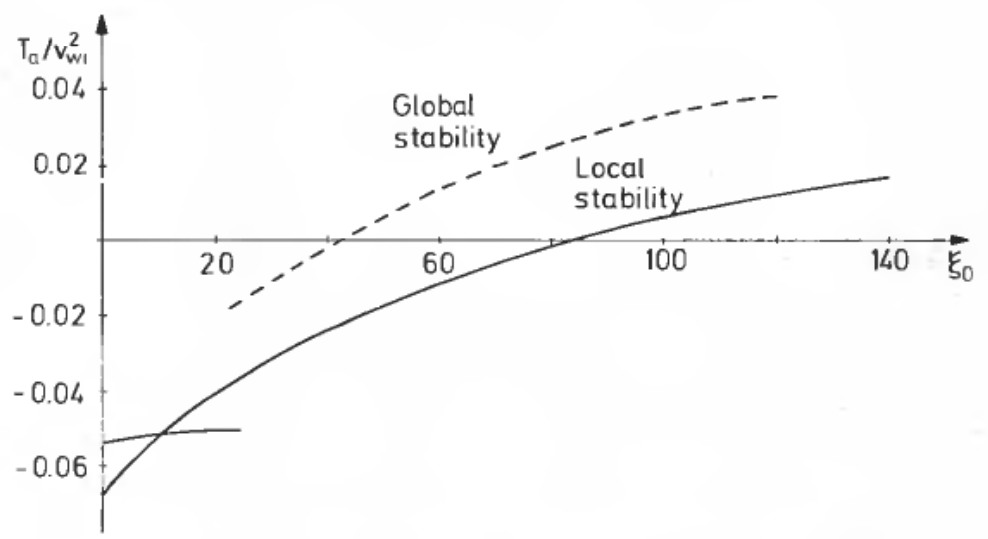

Figure 9. Effect of non-linearities on stability in wind.

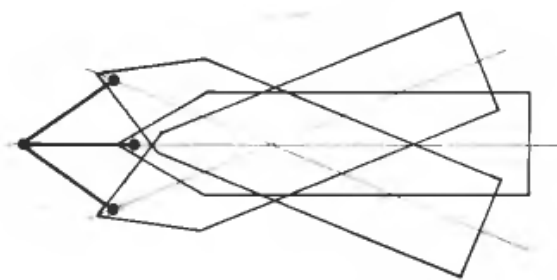

Fish tailing

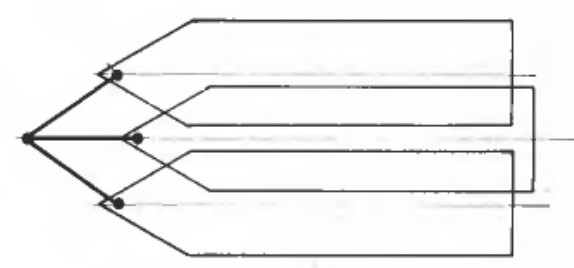

Galloping

Figure 10. Characteristic motions of moored ship.

The tendency is that motion amplitudes in stable oscillations increase with hawser length and decrease with increasing hawser tension. Furthermore, motions are typically larger in wind than in current. An example is presented in Figs. 11 and 12, showing yaw motion and position plot for the ballasted tanker with zero astern thrust and $55 \mathrm{~m}$ separation distance. Wind is the main destabilizing excitation.

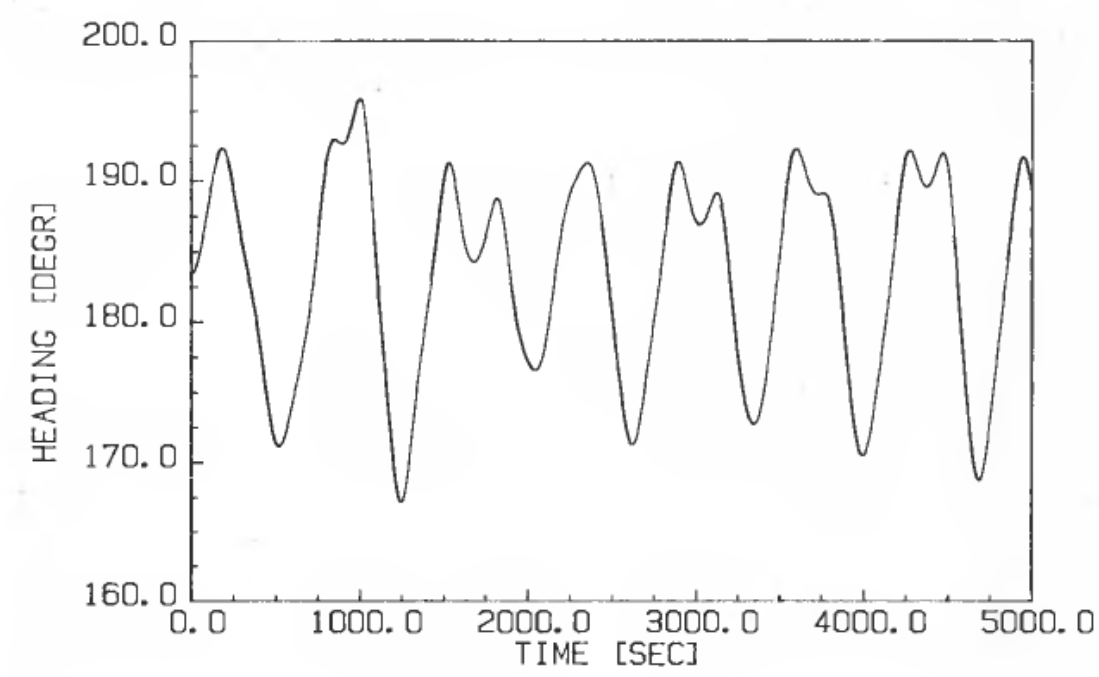

Figure 11. Yaw motion of ship in stable oscillations. 


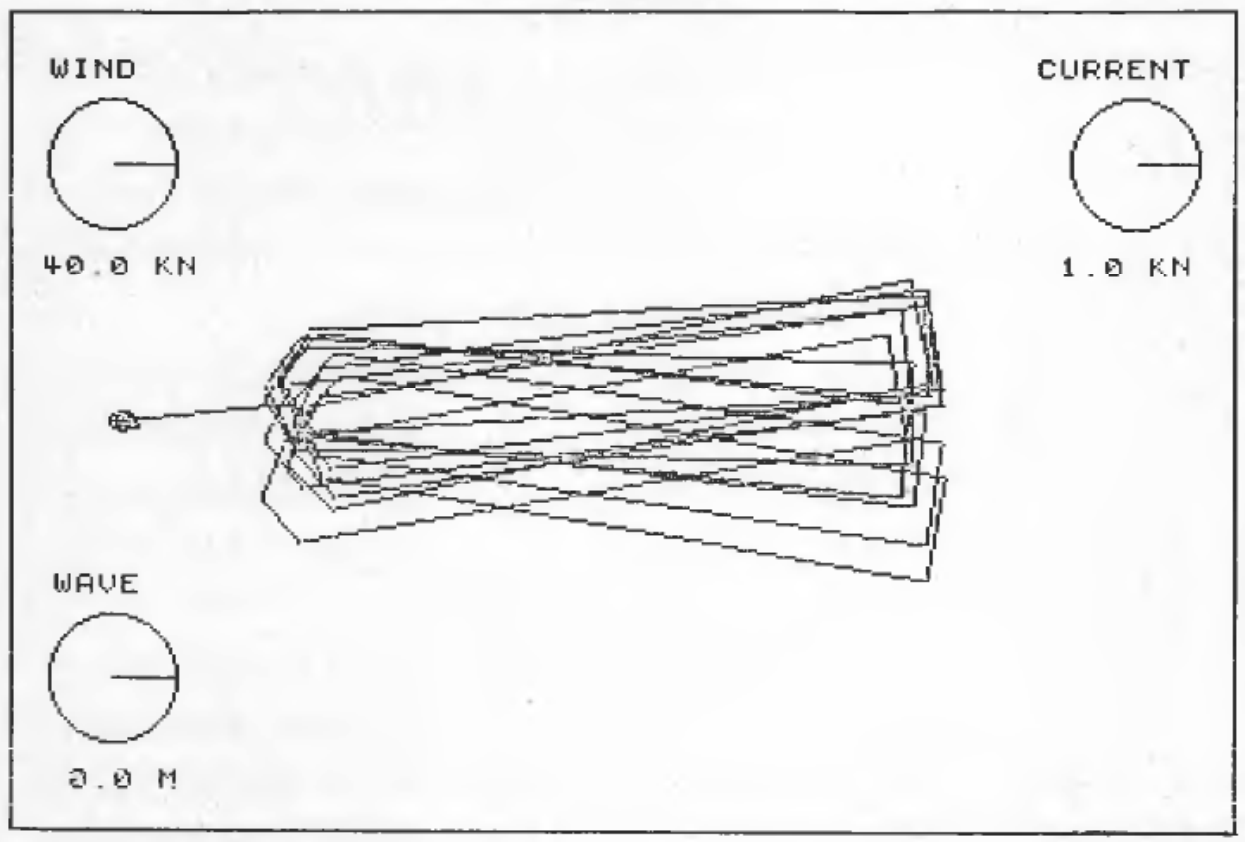

Figure 12. Position plot of ship in stable oscillations.

\subsection{Motion response to time varying excitations}

The low frequency components in wind and wave drift forces excite the slow ship motions when they coincide or near coincide with one or more of the characteristic system periods. Increased astern thrust generally reduces low frequency motions; however, increasing amplitudes have also been observed during simulations, which are probably due to some resonance phenomenon.

Only modes which have relatively small damping are excited. In an asymptotically stable system, low frequency motions are therefore mainly in surge, and only when the angle of attack of wind or waves is small.

In the last example, the combined effect of high and low frequency motions from time varying excitations are illustrated.

\section{Example}

Excitation:

$$
\text { wind: } 20 \mathrm{~m} / \mathrm{s}, 315^{\circ}
$$

gust: $\sigma_{v}=2 \cdot 4 \mathrm{~m} / \mathrm{s}$

$$
\sigma_{\dot{\psi}}=3.4^{\circ}
$$

wave: $H_{\frac{1}{3}}=5.5 \mathrm{~m}, 0^{\circ}$ P.M. spectrum

current: $\quad 0.25 \mathrm{~m} / \mathrm{s}, 315^{\circ}$

Equilibrium position: heading: $\psi_{0}=150 \cdot 3^{\circ}$

$$
\gamma_{0}=-3 \cdot 9^{\circ}
$$

mooring line: $\xi_{0}=74.1 \mathrm{~m}$

$I_{0}=64.8 \mathrm{~m}$

$l_{00}=55.0 \mathrm{~m}$

$F_{0}=50 \cdot 9$ ton 
astern thrust: $T_{\mathrm{a}}=15 \cdot 0$ ton

Characteristic periods and damping: $279 \mathrm{~s}, 2 \cdot 0 \%$ of critical $375 \mathrm{~s}, 6.2 \%$ of critical $599 \mathrm{~s}, 19.1 \%$ of critical

Ship yaw motion, $\psi\left(^{\circ}\right)$, and hawser tension, $\boldsymbol{F}$ (ton), are shown in Figs. 13 and 14. The high frequency component in $F$ is shown more clearly in expanded time scale (five times) in Fíg. 15.

Maximum tension is about 150 ton and low frequency yawing has double amplitudes of $20-25^{\circ}$ (double amplitude of relative hawser direction, $\gamma$, is $50^{\circ}$ ). The slow oscillations in this example are dominated by the second-order wave forces in surge and yaw. These forces are uncertain and possibly too large.

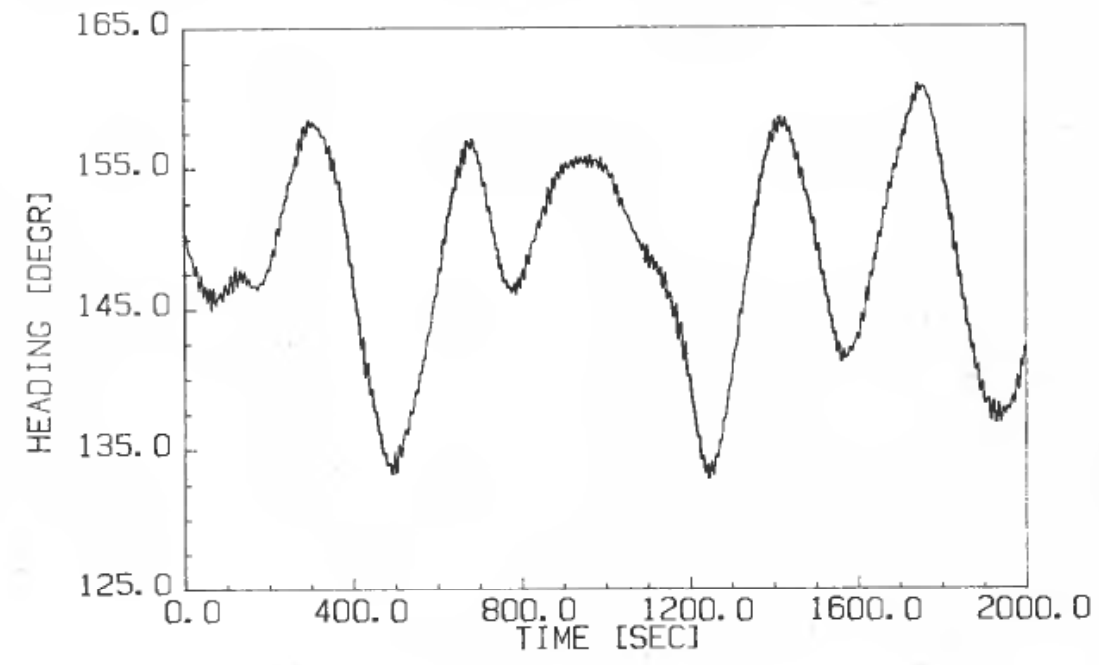

Figure 13. Yaw motion of ship to time varying excitations.

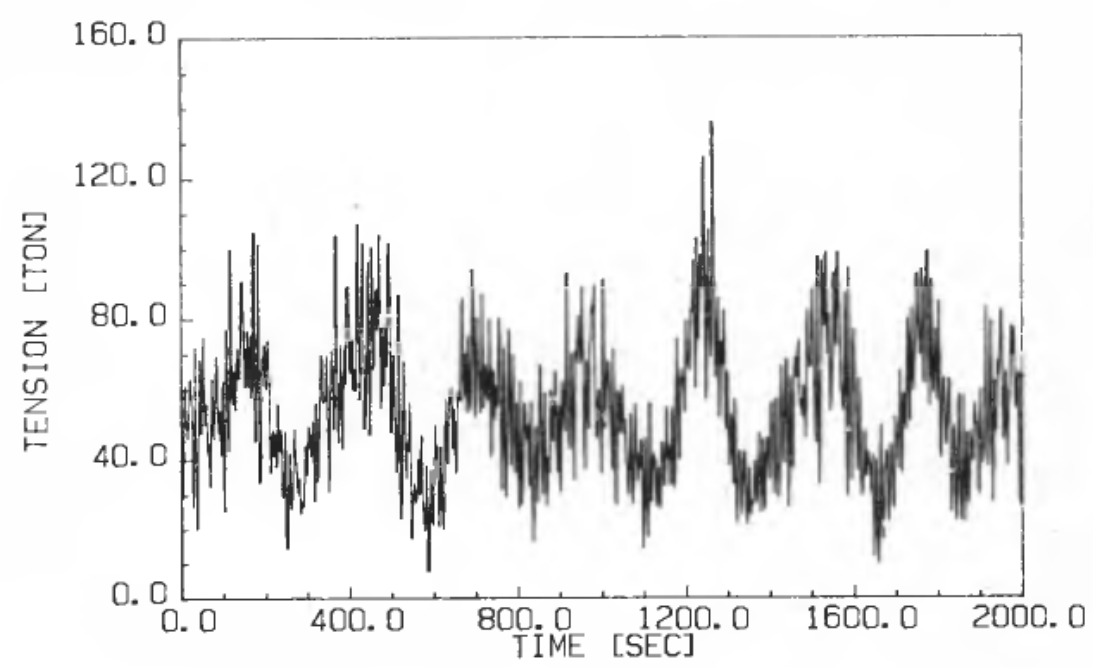

Figure 14. Hawser tension to time varying excitations.

M.I.C. 


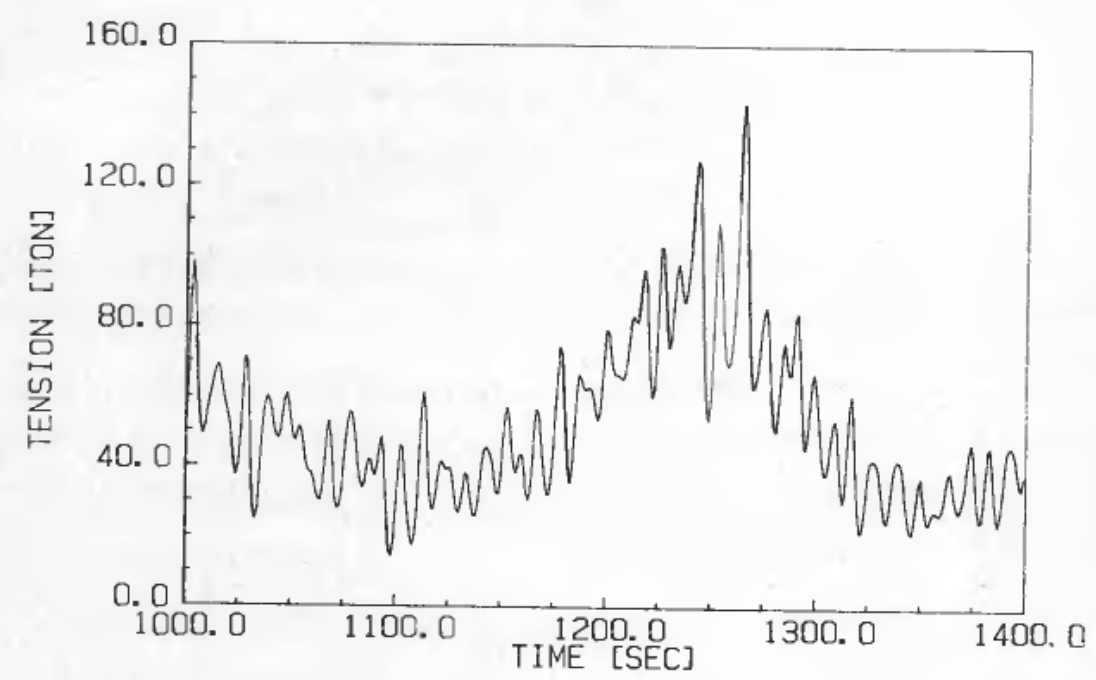

Figure 15. Hawser tension to time varying excitations. Expanded time scale.

\section{Conclusion}

A mathematical model for analysis of motions and mooring forces in single-point mooring systems has been described. Some general tendencies of ship stability in single-point mooring are given by a single formula assuming small motion amplitudes and zero damping. More accurate analysis requires estimation of hydrodynamic damping forces. Non-linear effects are significant for prediction of asymptotic stability in wind. Low frequency wind and wave force variations excite the slow motions in the system when the direction of ship and excitations are collinear.

\section{ACKNOWLEDGMENTS}

This work has been sponsored by the Royal Norwegian Council for Scientific and Industrial Research and by Kongsberg Våpenfabrik. The author also wishes to thank Statoil for submission of General Arrangement data and results from model tests, and Det norske Veritas for providing relevant ship responses in waves.

\section{Appendix}

Model of slowly varying motions of ships in single-point mooring (symbols and detailed force descriptions are given in the text).

Kinematics:

Dynamics:

$$
\begin{aligned}
\dot{x}_{r} & =u \cos \psi-v \sin \psi+v_{\mathrm{cu}} \cos \psi_{\mathrm{cu}} \\
\dot{y}_{r} & =u \sin \psi+v \cos \psi+v_{\mathrm{cu}} \sin \psi_{\mathrm{cu}} \\
\psi & =r
\end{aligned}
$$

$$
\begin{aligned}
& m\left(\dot{u}-v r-x_{g} r^{2}\right)=X_{\text {id }}+X_{\text {visc }}+X_{\text {wind }}+X_{\text {wave }}+X_{\text {hawser }}+X_{\text {manoeuvring }} \\
& m\left(\dot{v}+u r+x_{g} \dot{r}\right)=Y_{\text {id }}+Y_{\text {lift }}+Y_{\text {cross-flow }}+Y_{\text {wind }}+Y_{\text {wave }}+Y_{\text {hawser }}+Y_{\text {manoeuvring }} \\
& m k^{2} \psi \dot{r}+m x_{g}(\dot{v}+u r)=N_{\text {id }}+N_{\text {lift }}+N_{\text {cross-flow }}+N_{\text {wind }}+N_{\text {wave }}+N_{\text {hawser }}+N_{\text {manoeuvring }}
\end{aligned}
$$




\section{REFERENCES}

Aвкоwitz, M. A. (1964). Lectures on ship hydrodynamics. Steering and manoeuvrability. Hydro- and Aerodynamic Lab. Report No. Hy-5.

BERG, T. E., and UTNES, T. (1978). A note on added mass calculation in connection with linear theory for manoeuvring ship. Division of Marine Hydrodynamics, The Norwegian Institute of Technology.

BERLEKOM, W. B. VAN (1975). Effects of propeller loading on rudder efficiency. Proceedings from 4th Ship Control Symposium, Haag.

BerleKom, W. B. VAN, and GODDARD, T. A. (1972). Manoeuvring of large tankers. Trans. $S N A M E, 80$.

Berlekom, W. B. Van, TrägÅrdh, P., and Dellhag, A. (1974). Large tankers-wind coefficients and speed loss due to wind and sea. RINA, pp. 41-58.

Brummer, G. M. A., Voorde, C. B. van de, WiJK, W. R. van, GlanSdorP, C. C. (1972). Simulation of the steering and manoeuvring characteristics of a second generation container ship. Netherlands Ship Research Centre TNO, Report No. 170s.

CRANE, C. L. (1966). Studies of ship manoeuvering: 'Response to propeller and rudder actions'. Stevens Institute of Technology, Report No. AD 706571.

English, J. W. (1970). Moving ships sideways. Shipping World and Shipbuilder, April, pp. 549-555.

Faltinsen, O. M., KJaerland, O., Liapis, N., and Walderhaug, H. (1979). Hydrodynamic analysis of tankers in single-point-mooring systems. Proceedings from Behaviour of Offshore Structures, Trondheim.

FAltinsen, O. M., and LøKen, A. E. (1978). Drift forces and slowly varying forces on ships and of fshore structure in waves. Norwegian Maritime Res., 1.

Gerritsma, T., Beukelman, W., and Glansdorp, C. C. (1974). The effects of beam on the hydrodynamic characteristics of ship hulls. Proceedings from Symposium on Naval Hydrodynamics, London.

GLANSDORP, C. C. (1975). Ship type modelling for a training simulator. Proceedings from 4 th Ship Control Systems Symposium, Haag, 4, 117.

Haring, R. E. (1976). Single-point tanker mooring measurements in the North Sea. Proceedings from Offshore Technology Conference, Houston, paper no. 2711.

Hsu, F. H., and BLENKARN, K. A. (1970). Analysis of peak mooring forces caused by slow vessel drift oscillations in random seas. Proceedings from Offshore Technology Conference, Houston, paper no. 1159.

KapteIJn, S. A. T. (1976). Offshore loading systems. Offshore North Sea Conference, Stavanger.

KOONCE, K. T. (1976). Technology needs for deepwater operations. Proceedings from Behaviour of Offshore Structures, Trondheim.

LeniHAN, J. H. (1975). The role of single point moors in the North Sea. Society of Petroleum Engineers of AIME, SPE 5261.

MAARI, R. (1975). Offshore Mooring Terminals. (Monaco: Single Buoy Moorings Inc.).

MinkenberG, A. L., and Gie, T. S. (1974). Will the 'regular wave concept' yield meaningful motion predictions for offshore structures? Proceedings from Offshore Technology Conference, Houston, paper no. 2040.

MugA, B. J., and FreEman, M. A. (1977). Computer simulation of single point moorings. Proceedings from Offshore Technology Conference, Houston, paper no. 2829.

Newman, J. N. (1977). Marine Hydrodynamics. (Cambridge: MIT).

NorrbiN, N. H. (1971). Theory and observations on the use of a mathematical model for ship manoeuvring in deep and confined waters. The Swedish State Shipbuilding Expermental Tank, Göteborg, Publication No. 68.

OCIMF (1976). Prediction of Wind and Current Loads on VLCC's. Oil Company International Marine Forum.

Oortmersen, G. van, and Remery, G. F. M. (1973). The mean wave, wind and current forces on offshore structures and their role in the design of mooring systems. Proceedings from Offshore Technology Conference, Houston, paper no. 1741.

OWEN, D. G., and LINFOOT, B. T. (1976). The development of mathematical models of singlepoint mooring installations. Proceedings from Offshore Technology Conference, Houston, paper no. 2490. 
Pinkster, J. A., and Remery, G. F. M. (1975). The role of model tests in the design of single point mooring system. Proceedings from Offshore Technology Conference, Houston, paper no. 2212.

SANTEN, J. A. VAN, and KeRK, K. DE (1976). On the typical qualities of SPAR type structures for initial or permanent field development. Proceedings from Offshore Technology Conference, Houston, paper no. 2716.

SigBJøRNSON, R. (1975). On the wind structure in marine environments. SINTEF Report No. STF48 A75041, Trondheim.

Smitt, L. W., and ChisleTt, M. S. (1974). Large amplitude PMM tests and manoeuvering predictions for a mariner class vessel. 10th Symposium on Naval Hydrodynamics, Boston, pp. 131-151.

Wheeler, R. J., Taylor, A. A., McKenna, H. A., and Linehan, J. (1973). A floating pipeline-producing Ekofisk crude into tankers. Proceedings from Offshore Technology Conference, Houston, paper no. 1866.

Wichers, J. E. W. (1976). On the slow motion of tankers moored to single point mooring systems. Proceedings from Offshore Technology Conference, Houston, paper no. 2548.

Woehleke, S. P., Flory, J. F., and Sherrard, J. R. (1978). Hawser system design for single point moorings. Proceedings from Offshore Technology Conference, Houston, paper no. 3156. 